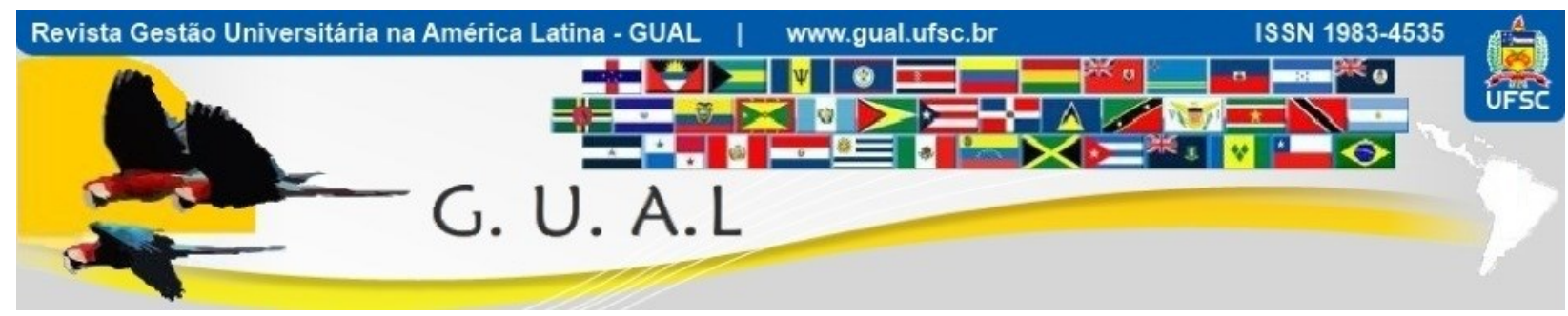

DOI: http://dx.doi.org/10.5007/1983-4535.2020v13n1p93

\title{
O MOVIMENTO ESTUDANTIL ENQUANTO FORMA ORGANIZACIONAL DE LUTA E RESISTÊNCIA: O CASO DO "OCUPAUF"
}

\section{THE STUDENT MOVEMENT AS AN ORGANIZATIONAL FORM OF STRUGGLE AND RESISTANCE: THE CASE OF "OCUPAUF"}

Ana Paula Gonçalves Doro, Mestre https://orcid.org/0000-0003-2769-9432 anapdoro@gmail.com

Universidade Federal de Juiz de Fora | Faculdade de Administração e Ciências Contábeis Juiz de Fora | Minas Gerais | Brasil

Débora Magalhães Kirchmair, Mestre https://orcid.org/0000-0002-4736-3808 deboramkirchmair@gmail.com

Universidade Federal de Juiz de Fora | Faculdade de Administração e Ciências Contábeis Juiz de Fora | Minas Gerais | Brasil

Ângelo Brigato Ésther, Doutor https://orcid.org/0000-0001-9084-3746 angelobrigato@gmail.com

Universidade Federal de Juiz de Fora | Faculdade de Administração e Ciências Contábeis Juiz de Fora | Minas Gerais | Brasil

Yanne Cristina Ribeiro Orozimbo, Graduada https://orcid.org/0000-0001-9084-3746 yanneribeiro@hotmail.com

Universidade Federal de Juiz de Fora | Faculdade de Administração e Ciências Contábeis Juiz de Fora | Minas Gerais | Brasil

Recebido em 09/agosto/2018

Aprovado em 15/outubro/2019

Publicado em 02/janeiro/2020

Sistema de Avaliação: Double Blind Review

c) (†) $\ominus$ Esta obra está sob uma Licença Creative Commons Atribuição-Uso. 


\title{
RESUMO
}

As formas organizativas destoantes da lógica de mercado, apesar de marginalizadas, constituem um campo fértil de estudos. O objeto deste artigo é o movimento de ocupação ocorrido em uma universidade federal localizada em Minas Gerais, motivado pela votação da Proposta de Emenda à Constituição (PEC) 241 do governo Michel Temer, a qual previa o congelamento dos gastos com saúde e educação no Brasil durante 20 anos. Buscou- se compreender a estrutura e a dinâmica do referido movimento que realizou a ocupação do espaço da universidade como forma de resistência. Os resultados apontam para práticas organizativas horizontais, com predomínio da tomada de decisão coletiva e para o fortalecimento do movimento estudantil.

Palavras-chave: Movimento Estudantil. Movimentos Sociais. Ocupação. Autogestão.

\begin{abstract}
The objective of this paper is to understand how the rectory of a Brazilian federal university took place. It is a student movement in which the occupation of university space was used as an instrument of resistance to the neoliberal practices proposed by the government. The review of literature refers to the following points: student movement and worker's self management. This is a qualitative research, based on a case study developed from the observation of the space occupied and the testimony of the interviewees. The results point to horizontal organizational practices, with a predominance of collective decision making, and to the strengthening of the student movement.
\end{abstract}

Keywords: Student Movement. Social Movements. Worker's Self Management. 


\section{INTRODUÇÃO}

A lógica de mercado é tida como inquestionável na organização de todas as dimensões da vida social. As organizações dominantes, pautadas pelas características do modelo burocrático, têm o mercado como força central (SILVA, 2016). Nesse sentido, a definição de organização tem sido reduzida ao viés da formalidade estrutural (MISOCZKY; FLORES; SILVA, 2008). Assim, o termo remete a estruturas burocráticas onde predominam a hierarquia, a centralização das decisões, a formalidade, a rigidez e a departamentalização.

Entretanto algumas estruturas organizativas desenvolvem-se a partir de um modelo que não segue os preceitos tipicamente burocráticos, como os movimentos sociais, os coletivos e as experiências de economia solidária. Tais organizações tendem a ser invalidadas e invisibilizadas. Em alguns casos, são chamadas, pejorativamente de "marginais" ou “alternativas" (COSTA, 2015).

As formas de organizar destoantes da lógica dominante constituem um caminho de muitas possibilidades de estudo, embora Misoczky, Silva e Flores $(2008$, p.1) ressaltem a dificuldade de percepção de arranjos organizacionais diferentes daqueles dominantes: "Obcecados com o hierarquismo, somos incapazes de reconhecer práticas organizacionais existentes na prática, mas às margens de nosso arcabouço teórico". Dessa forma, a racionalidade que sustenta as teorias tradicionais, focadas no interesse egoístico e no cálculo instrumental, não reconhece práticas organizativas pautadas por convicções baseadas em valores. Os autores defendem o engajamento dos pesquisadores nos movimentos populares e em reflexões que contribuam para um projeto de mudança radical, tornando visíveis os processos de organizações de resistência e de lutas sociais, processos esses que tendem a ser desconsiderados no discurso organizacional (MISOCZKY; FLORES; SILVA, 2008).

Misoczky, Flores e Silva (2008, p.10) questionam a utilização de teorias do mundo dos negócios nas abordagens de movimentos sociais, visto que elas não possuem lentes que expliquem "práticas organizativas não estruturadas, não duradouras, sem lideranças empreendedoras e para as quais não se consegue identificar relações racionais de custobenefício". O sucesso nessa lógica está associado ao atingimento de objetivos explícitos e não se valoriza, por exemplo, transformações culturais importantes na sociedade.

Nessa perspectiva, conforme destacado por Misoczky (2010) o termo “organizar" não significa organizar burocraticamente. Evitar essa redução faz-se necessário, utilizando assim uma definição mais ampla, como a adotada pelos autores: “organizar é produzir socialmente 
modos de cooperação, sempre instáveis e em movimento". Assim, os objetos dos estudos organizacionais podem ser ampliados (MISOCZKY, 2010, p.27). Defensores dessa concepção, aqueles autores afirmam que os movimentos sociais são formados por práticas organizacionais que não são compreendidas utilizando os formatos atuais desses estudos. $\mathrm{Na}$ mesma linha de pensamento, Barros e Paes de Paula (2008) corroboram com a ideia de que esses movimentos são organizações, destacando que talvez seja neles que ela se manifeste verdadeiramente, uma vez que a participação é voluntária e as ideias são compartilhadas. Os autores denominam os movimentos sociais como organização social.

A respeito das diferenças entre organizações produtivas ${ }^{i}$ e movimentos sociais, Barros (2009, p. 23) ressalta que:

[...] estes podem se organizar em torno de ideais e sem ter um fim imediato aparente, ao contrário das organizações produtivas que são regidas pelas leis capitalistas, que exigem o lucro e o consequente fechamento dos ciclos de reprodução ampliada do capital. Acrescente-se que os movimentos sociais não são institucionalizados à maneira das empresas, que criam regulamentos e códigos de conduta, por exemplo, para pautar o comportamento de seus funcionários. No movimento social, a liberdade de ação é tendencialmente mais ampla, enquanto que os sujeitos não são coagidos a se integrar nestas, ao passo que as pessoas se veem premidas pela necessidade econômica a vender sua força de trabalho às organizações produtivas, não tendo muitas alternativas.

No entanto, o autor reforça que não é possível um total desligamento dos movimentos sociais da lógica estabelecida no mercado e no Estado. Assim, certo grau de pragmatismo é presente, todavia, não é necessariamente a característica proeminente (BARROS, 2009).

Tendo em vista essas constatações, o objeto desse estudo é o movimento de ocupação ocorrido numa universidade federal localizada em Minas Gerais, motivado pela votação da Proposta de Emenda à Constituição (PEC) 241 do governo Michel Temer, a qual previa o congelamento dos gastos com saúde e educação no Brasil durante 20 anos. Este governo tem priorizado a adoção de medidas consideradas neoliberais não aceitas por pessoas que defendem uma atuação mais efetiva do Estado no atendimento das demandas e necessidades da população.

O movimento estudado faz parte de uma série de resistências que ocorreram no país no ano de 2016, quando, de acordo com informações divulgadas pela União Nacional dos Estudantes (UNE), pelos menos 220 universidades foram ocupadas, além de 1000 escolas secundaristas. 
O objetivo deste trabalho é compreender a dinâmica e a estrutura do movimento de ocupação numa universidade federal, sob o nome fictício de OcupaUF. Essa compreensão é importante para esclarecer como movimentos locais podem se articular para mobilização frente a pautas nacionais.

\section{A AUTOGESTÃo COMO ESTRUTURA ORGANIZATIVA DOS MOVIMENTOS SOCIAIS}

Os movimentos sociais representam um dos formatos de organização da civil, a respeito dos quais discutiu Scherer-Warren (2006). O autor destaca seus diferentes níveis presentes no Brasil: o "associativismo local" é colocado como sendo o primeiro, que expressa uma organização local, e nele encontram-se associações civis, movimentos comunitários e sujeitos ligados a questões culturais ou sociais, ONG's ou associações ligadas ao terceiro setor. O segundo nível é composto por "formas de articulação inter-organizacionais", às quais pertencem fóruns da sociedade civil, associações nacionais de ONG's e as redes de redes. Esse nível age como formas de representação de movimentos e associações locais, funcionando assim como um elo entre sociedade civil e o Estado. Em um terceiro nível, estão protestos que tem maior abrangência, denominados de "mobilizações na esfera pública". A respeito desses, Scherer-Warren (2006, p.112) destaca:

\footnotetext{
Nesse terceiro nível, observa-se que as mobilizações na esfera pública são fruto da articulação de atores dos movimentos sociais localizados, das ONGs, dos fóruns e redes de redes, mas buscam transcendê-los por meio de grandes manifestações na praça pública, incluindo a participação de simpatizantes, com a finalidade de produzir visibilidade através da mídia e efeitos simbólicos para os próprios manifestantes (no sentido políticopedagógico) e para a sociedade em geral, como uma forma de pressão política das mais expressivas no espaço público contemporâneo.
}

No quarto nível estão os "apoios financeiros" representados principalmente pelas agências não governamentais e governamentais, e também colaborações individuais. A articulação desses diversos níveis dá origem ao que a autora denomina de "rede de movimento social". Assim, o movimento social, sob um ponto de vista mais abrangente, "se constitui em torno de uma identidade ou identificação, da definição de adversários ou opositores e de um projeto ou utopia, num contínuo processo em construção e resulta das múltiplas articulações acima mencionadas" (SCHERER-WARREN, 2006, p.113). 
Diante das particularidades do formato organizacional dos movimentos sociais, faz-se necessário a utilização de categorias de análises diferentes do modo burocrático dominante para a compreensão dos aspectos organizativos desses movimentos, ou organizações sociais. Nesse sentido, conforme destacado por Motta (1981, p. 10) "a característica fundamental da administração burocrática é a heterogestão e sua única alternativa radical é a autogestão".

Misoczky (2010) refletem que a autogestão tem sido utilizada de forma restrita nos Estudos Organizacionais, abarcando, sobretudo processos produtivos. Os autores apontam para a necessidade desses estudos contemplarem processos de resistência e das lutas sociais, questionando dessa forma o uso comum da organização como sinônimo de empresa.

O termo autogestão não é recente, mas foi utilizado para designar formas de organização social e produtiva em diversos momentos da história como as experiências da Comuna em Paris, na Revolução Russa, em propostas anarquistas, nos falanstérios ${ }^{\mathrm{ii}}$, na Iugoslávia de Tito, entre outros (TOLEDO, 2008). Gutierrez (1988) aponta que a autogestão pressupõe a busca pela diminuição da separação entre o trabalho manual e o intelectual, considerando o homem como um ser completo. Dessa forma, o sofrimento causado pela utilização parcial das potencialidades humanas, defendido pela divisão taylorista do trabalho, é evitado, assim como a alienação do trabalhador. Pinheiro e Paula (2016, p.235) ressaltam que as organizações autogestionárias são "iniciativas de cunho econômico e social, que buscam estabelecer relações solidárias, democráticas e equitativas, movendo-se não apenas para alcançar resultados econômicos, mas também sociais, políticos culturais e formativos".

Para Misoczky, Silva e Flores (2008) nessas estruturas organizativas prevalecem práticas horizontais. Os autores apontam como principais características das práticas organizacionais horizontais:

Entre as categorias fundamentais que constituem as práticas organizacionais horizontais podem ser destacadas: Assembléia Geral como órgão deliberativo máximo; delegação autorizada para cargos temporários, revogáveis a qualquer tempo; regras determinadas em Assembléia, isto é, pelo coletivo; igualdade de participação ou poder de decisão; tomada de decisão por consenso e em último caso por votação; compartilhamento das informações por todos; inseparabilidade entre os meios e o coletivo organizacional; documentação dos processos administrativos e sua ampla divulgação; instâncias explícitas de tomada de decisão (MISOCZKY, SILVA; FLORES, 2008, p.13). 
O processo decisório coletivo é uma característica presente em estruturas organizativas que enfrentam que enfrentam a lógica dominante (SERVA, 1993; MISOCZKY, 2010). As decisões não devem ser atreladas a interesses pessoais, mas sim a interesses coletivos, utilizando constantemente a busca de consensos. Em outras palavras, "as decisões não são tomadas pelos líderes ou por algum tipo de comissão dirigente, seu papel é implementar os acordos coletivos" (MISOCZKY, 2010, p.26). Dessa forma, não basta apenas a realização de votações em assembleias, mas deve haver a busca pelo consenso. Os participantes devem exprimir os seus desejos e, para isso, é importante a formação política dos membros da organização, a fim de que eles próprios possam lutar e defender seus interesses.

Este estudo busca discutir a ocorrência de práticas de autogestão em uma manifestação realizada por estudantes de graduação em uma universidade federal. Por isso, faz-se necessário uma contextualização a respeito do movimento estudantil no Brasil.

\section{O MOVIMENTO ESTUDANTIL NO BRASIL}

Representante da luta contra a ordem dominante, o movimento estudantil brasileiro está inserido no contexto de mobilizações sociais vivenciadas, sobretudo a partir da segunda metade do século XX. Conforme destacado por Freire (2008), este movimento teve seu auge na década de 1960 na luta contra a ditadura militar.

Barros (2009) destaca o papel fundamental que as manifestações estudantis tiveram em épocas variadas da história do Brasil, como nas lutas antifascistas na Segunda Guerra Mundial, na campanha pelo monopólio do petróleo, na resistência à ditadura militar e no movimento "Diretas já". Diversos autores, entre eles Barros (2009), Freire (2008) e Mesquita (2003) apontam a década de 1960 como a época de maior expressividade desse movimento no país. Entretanto, conforme ressalta Scherer-Warren (2014), a luta da juventude na busca por modificações nos sistemas social, cultural e político, não é recente.

As primeiras evidências do movimento estudantil no Brasil datam de 1710, quando vários estudantes, integrantes dos conventos religiosos, se juntaram para expulsar invasores franceses dos colégios e das moradias que os abrigavam, no Rio de Janeiro. No país, no período Colonial (1500-1822), os jovens participaram da Inconfidência Mineira (1788) (UNICAP, 2017).

Segundo a União Nacional dos Estudantes (UNE) (2017), em 1808, surge o primeiro curso superior brasileiro. Durante todo o século 19, o ensino esteve extremamente restrito e se 
caracterizava por grande influência religiosa. Contudo, no século seguinte, o Brasil viveu um forte crescimento da industrialização e das cidades e, consequentemente, uma ascensão do número de estudantes. Este crescimento revelou-se como um incentivo para os jovens se organizarem coletivamente e interagir com questões relacionadas ao país. Em 1901, foi criada a Federação dos Estudantes Brasileiros que, apesar de ter breve duração, foi importante para a visibilidade da importância do movimento estudantil brasileiro. Costa (2004) ressalta, que apesar da tentativa dos estudantes de tentarem se unir, ainda não existiam organizações de caráter definitivo, formalmente constituídas por eles. A mobilização estudantil se dava isoladamente através de organizações sociais já existentes ou que eram fundadas para atuar em fins sociopolíticos específicos. Havia também grupos de estudantes de diversas escolas que se posicionavam transitoriamente em prol de uma causa particular. Assim, tais formas de associação dificultavam a consolidação dos ideais estudantis que seriam capazes de manter ativas tais organizações.

Com a revolução de 1930, intensificou-se a politização destes estudantes, o que provocou a maior atuação deles em representações. Dentre elas, se destacam a Juventude Comunista e a Juventude Integralista. Houve então, o aumento do desejo em unificar a luta pela qualidade do ensino, pelo patrimônio nacional e pela justiça social. No entanto, apenas no dia 11 de agosto de 1937, na Casa do Estudante do Brasil (CEB) situada no Rio de Janeiro, criou-se uma entidade máxima representativa, forte e legitima que foi denominada União Nacional dos Estudantes (UNE) (UNE, 2017).

Como reação a articulação dos estudantes, em 1964, os militares atacaram a sede da UNE na Praia do Flamengo, representando a primeira ação da ditadura civil-militar contra o movimento. Dessa forma, o país se tornou cenário de forte repressão aos brasileiros muitos deles estudantes. Neste mesmo ano foi outorgada a Lei Suplicy de Lacerda a qual retirava legalmente a representatividade da UNE que passou a atuar na ilegalidade, em firme oposição ao regime (UNE, 2017). Com a extinção da UNE, limitando a atuação dos estudantes, associada a outras questões como demissões arbitrárias de professores, os jovens se articularam em grandes manifestações pelo país (FREIRE, 2008).

Segundo Martins e Ruiz (2015) durante este período, algumas medidas repressivas foram aplicadas aos opositores do regime, como por exemplo, a perseguição política; supressão de direitos constitucionais; o exílio de cidadãos; censura; tortura; fechamento de entidades; invasão de sindicatos; inibição da autonomia e representatividade do movimento 
estudantil. Segundo a UNE (2017), as universidades eram vigiadas, intelectuais e artistas reprimidos, o Brasil se escurecia. Prática comum, a violência foi gravemente utilizada para reprimir o movimento e por meio das leis e dos Atos Institucionais, o cenário se piorava.

Contudo, ao final dos anos 1970, o regime militar foi se desvitalizando e a UNE começou a se reestruturar de forma lenta e gradual. Prova disso foi o acontecimento do congresso de reconstrução da entidade que ocorreu em 1979, na cidade de Salvador. As pautas eram em prol de mais recursos para a universidade, da defesa do ensino público e gratuito, bem como a exigência pela libertação dos estudantes presos (UNE, 2017).

Em 4 de novembro de 1985, o presidente José Sarney sancionou a Lei 7398 que dispõe sobre a organização de entidades representativas dos estudantes de $1^{\circ}$ e $2^{\circ}$ graus assegurando “a organização de Estudantes como entidades autônomas representativas dos interesses dos estudantes secundaristas com finalidades educacionais, culturais, cívicas esportivas e sociais" (BRASIL, 1985). Neste contexto, amparados pela criação desta lei, de acordo com UNIFESP (2017), entre 1986 e 1988, a UNE e a União Brasileira dos Estudantes Secundaristas (UBES) foram reorganizando o movimento de base, por meio da reabertura ou suporte na criação de entidades de base como Centros e Diretórios Acadêmicos e Grêmios Estudantis.

Barros (2009) destaca que o último momento em que o movimento estudantil notabilizou-se foi na ação "Fora Collor", em 1992. Na percepção do autor, após esse fato nota-se uma acomodação por parte dos estudantes:

Após ter sobrevivido por vários anos na clandestinidade durante a ditadura militar brasileira e de ter voltado à legalidade, as lutas estudantis parecem estar fragmentadas e com pouco potencial de transformar a realidade e, mesmo, de ocupar lugares importantes nas discussões no interior e a respeito da universidade (BARROS, 2009, p.69)

Na concepção de Mesquita (2003), não é possível falar de um movimento estudantil atual como unitário, mas sim de uma pluralidade de grupos, na qual existe uma inter-relação entre eles. $\mathrm{O}$ autor aponta que ao mesmo tempo em que essa diversidade revela-se positivamente, pois abarca cada vez mais grupos heterogêneos, ela apresenta-se como um desafio para as entidades estudantis clássicas. Nessas, há uma dificuldade de acolhimento de novas formas de expressões estudantis. Além disso, o autor ressalta que apesar desse movimento ter absorvido aspectos de novos movimentos sociais, ele apresenta-se fragmentado, não conseguindo reunir uma parte expressiva de estudantes: "O movimento 
passa assim, por uma crise de representatividade e organicidade que se manifesta na sua intervenção fragmentada e na pouca expressividade entre os estudantes" (MESQUITA, 2003, p.121).

Para Scherer-Warren (2014), nos movimentos que ocorrem no século XX, havia um aspecto comum, de caráter coletivo. Analisando as manifestações ocorridas no Brasil em 2013, a autora aponta que essa característica não se apresentou da mesma forma, sendo notória uma fragmentação e até mesmo antagonismos. Nesse cenário, predominou a pluralidade de demandas.

Assim, conforme apontado por Mesquita (2003), diferente do movimento estudantil do passado, onde prevalecia uma estrutura de organização mais rígida e hierárquica, hoje ele apresenta-se de forma mais autônoma, democrática e horizontal. Por consequência, o autor aponta a necessidade de mudanças das estruturas das entidades tradicionais, a fim de incorporar os desejos e a diversidade da juventude atual.

Apesar da dificuldade de articulação do movimento estudantil atual, é possível perceber a emergência de ações de resistência às práticas hegemônicas. Neste contexto, encontra-se o OcupaUF, que será o objeto de discussão a seguir.

\section{MÉTODO DE PESQUISA}

O presente trabalho foi desenvolvido a partir de uma metodologia de pesquisa qualitativa. Quanto aos objetivos a pesquisa pode ser classificada como descritiva e em relação aos procedimentos técnicos utilizados trata-se de um estudo de caso. De acordo com Gil (2002) o estudo de caso é uma modalidade de pesquisa que é profunda e exaustiva de um ou poucos objetos de forma que possibilite seu amplo e detalhado conhecimento.

O levantamento dos dados ocorreu em duas etapas. A primeira deu-se em novembro de 2016, durante o período da ocupação da reitoria da universidade. Nesse momento, buscouse conhecer sua motivação e estrutura, realizando, para isso, uma observação direta e 5 entrevistas. A segunda etapa ocorreu em janeiro de 2017, quando voltou-se a campo para um novo levantamento de dados, logo após o fim da ocupação. Nesse momento foram realizadas mais 9 entrevistas com ex-ocupantes, selecionados por acessibilidade. Dentre estes, 2 foram entrevistados nas duas etapas. Assim, foram entrevistadas ao todo 12 estudantes, sendo 7 mulheres e 5 homens, dos cursos de Letras, Ciência da Computação, Serviço Social, Geografia, Ciências Humanas, Direito, Jornalismo, História e Cinema. 
A definição do número de entrevistas ocorreu pelo critério de "saturação", ou seja, atingiu-se o ponto em que as informações estavam se repetindo, não havendo novas descobertas. As entrevistas foram gravadas com consentimento dos entrevistados para posterior transcrição e análise. Além disso, utilizou-se da análise documental ao investigar a página oficial dessa ocupação na rede social Facebook.

Para analisar as entrevistas, foi utilizada a análise de conteúdo. Segundo Vergara (2012, p.7) "a análise de conteúdo é considerada uma técnica para o tratamento de dados que visa identificar o que está sendo dito a respeito de determinado tema". De acordo com a autora, é possível ter três tipos de grades para a análise: fechada, aberta ou mista. Neste trabalho, utilizou-se a grade aberta em que as categorias de análise vão sendo identificadas conforme vão surgindo ao pesquisador, sendo possível uma reorganização delas no decorrer da pesquisa.

\section{O OCUPAUF}

A organização OcupaUF faz parte da mobilização estudantil nacional ocorrida em 2016, durante o governo do presidente Michel Temer, e sua principal motivação foi a Proposta de Emenda a Constituição (PEC) $55^{\text {iii }}$, antiga PEC $241^{\text {iv }}$, que previa o congelamento de investimentos na saúde, educação e assistência social por 20 anos.

O movimento nacional, em novembro de 2016 era composto por 220 universidades. A proposta da reforma do ensino médio, expressa na Medida Provisória (MP) $746^{\mathrm{v}}$, entrou na pauta estudantil e assim, estudantes secundaristas também participaram das ocupações em mais de mil escolas em todo país (TADA, 2016). O movimento contou com diversas ações, entre elas a tomada da capital federal no dia 29 de novembro por cerca de 50 mil estudantes, trabalhadores, professores, sem teto e sem terra de diversas partes do país para expressão contra o que para eles representavam retrocessos do governo (BARS; TADA, 2016).

Nesse contexto, o OcupaUF foi formado a partir de uma assembleia convocada pelo Diretório Central dos Estudantes (DCE), em que participaram aproximadamente 600 estudantes da universidade no dia 26 de outubro de 2016. A discussão já estava ocorrendo nos Centros Acadêmicos (CAs) e Diretórios Acadêmicos (DAs), os quais realizaram uma reunião conjunta, na qual se estabeleceu que haveria a referida Assembleia. Na ocasião, os estudantes puderam manifestar suas ideias ao microfone e a assembleia durou cerca de quatro horas. Para votar, era necessário identificar-se como estudante da instituição. Quase a totalidade dos 
presentes votou a favor da ocupação e, já no primeiro dia, cerca de 250 pessoas ocuparam a reitoria da Universidade.

A organização OcupaUF foi motivada, principalmente, pelo cenário político nacional e a votação de medidas que impactariam na educação. Entretanto, foram também estabelecidas pautas internas, relativas ao contexto da universidade. O OcupaUF criou uma página na rede social Facebook, na qual reuniram as reinvindicações, informações internas e notícias sobre o cenário político do país foram divulgadas. Conforme divulgado nessa página, as pautas do OcupaUF foram:

- Contra o desmonte da educação, que vem ocorrendo através das PEC's 55 (antiga PEC 241) e $53^{\text {vi }}$ e das MP's 746 e $735^{\text {vii }}$.

- Contra o projeto de governo neoliberal de Michel (Fora) Temer

- Ampliação de políticas públicas para mães universitárias

- Revisão imediata da resolução das festas aprovadas em Consu ${ }^{\text {viii }}$

- Pelo apoio e construção de uma greve geral nacional

- Pela paridade do Consu

- Garantir que o prazo para liberação da moradia estudantil seja cumprido e planejamento da próxima moradia junto aos estudantes

- Repensar o modelo de segurança universitário, incluindo a participação efetiva de estudantes e da diretoria de ações afirmativas nas deliberações

- Pela inserção de medidas no RAG ${ }^{\text {ix }}$, que pautam os casos de assédio e agressão na universidade - independente de quem elas tenham partido

Os estudantes entrevistados relataram que o movimento provocou diversas reações entre a comunidade acadêmica e externa. Havia os que apoiavam, os que eram indiferentes e os que criticavam o movimento. Por exemplo, alguns opositores ao movimento afirmavam que na assembleia que resolveu pelo início do movimento não houve representatividade dos estudantes, visto que existem mais de 18.000 alunos na instituição e, nesse dia, compareceram cerca de 600. A despeito disso, o movimento recebeu retaliações:

A gente sofreu muitas críticas né? A gente sofreu críticas como do tipo: lá é um bando de maconheiros, um bando de estudante, vai caçar um trabalho, vai caçar alguma coisa pra você fazer, você está atrapalhando a minha universidade, é aquele pessoal de humanas [...] foram muitas críticas que a gente recebeu, e muitas críticas as vezes de pessoas que sequer conheciam o que que era o movimento, sequer perguntaram se a gente tava precisando de alguma coisa. (E1) 
Foi possível perceber a existência da pluralidade, característica marcante dos movimentos estudantis atuais, conforme apontado por Mesquita (2003) e Scherer-Warren (2014). Nesse sentido, havia grupos diversos que compunham o movimento com ideologias distintas e até divergentes, como organizações de militantes, partidos e coletivos (feministas, LGBT). Sobre a coexistência desses grupos no OcupaUF, um dos participantes relatou:

As forças têm rixas históricas, isso é algo que ocorre. Coisas da vida. Então, tinham organizações que não se batiam muito bem, não se davam muito bem, então refutavam algumas coisas, mas em grande maioria as forças coexistiram muito bem na ocupação. Não existiram grandes atritos, não existiram grandes brigas, nem rachas muito grandes. Não teve nenhuma discussão mais acalorada, por conta da organização, não teve nenhuma discussão que chegou até vias extremas, por conta de organização e por conta de outros problemas como discordância de visão, nem esse ponto. A gente brincava que a gente tava sentado em um paiol de pólvora, só que ele não explodiu. Graças! Porque ali a gente tinha forças antagônicas que lidaram muito bem com suas diferenças e suas discordâncias. (E4)

Mesmo com a existência da pluralidade de ideias, pode-se afirmar que o objetivo central do movimento - a resistência às propostas governamentais - constituiu o foco das discussões e decisões. Dessa forma, o movimento buscou, principalmente, se opor a uma forma de governar que eles acreditavam não ser benéfica para a maioria da população. Por isso, apesar de ter suas pautas, seu foco não foi se articular para o atingimento delas, mas sim compor um movimento de resistência que estava se articulando em todo o país:

Ao longo do processo a gente foi vendo que essa ocupação tinha um caráter totalmente diferente da última, porque [nessa] não tinha esse negócio de negociação com o Reitor, uma negociação mais direta [...] não havia assim, uma conjuntura e nem uma possibilidade de negociação direta, local. Acabou que ao longo do processo foi usando essas pautas [internas] como bandeiras que a gente apoia, mas que não são critérios de desocupação [...] acabou que a ocupação foi mais pra mobilização nacional (E3)

Nota-se uma tentativa de articulação com uma rede de movimentos locais que surgiram em todo o país. A universidade foi desfrutada como um espaço público para a expressão das insatisfações contra as medidas propostas pelo governo. O acampamento realizado na reitoria ganhou visibilidade na cidade, na comunidade acadêmica local, e as manifestações no Brasil de uma forma ampla, conquistaram um lugar na mídia nacional, caracterizando o movimento como uma "mobilização na esfera pública", segundo a classificação de Scherer-Warren (2006). 
Apesar dessa articulação com o movimento nacional, alguns entrevistados julgaram que houve incompetência do movimento para se mobilizar para o atingimento das pautas, sobretudo as internas: "Esse é um dos pontos muito fracos do movimento, ele foi cooptado pela conjuntura nacional e não deu muita atenção pra sua casa, não deu atenção para a universidade" (E7).

De acordo com os entrevistados, o modelo de organização adotado foi baseado na ocupação ocorrida na mesma universidade em 2015. No entanto, esta constou de um número menor de participantes e reinvidicou apenas pautas internas. Algumas pessoas complementaram ainda que a estrutura organizativa foi influenciada por outras ocupações que estavam ocorrendo, pois ocorriam trocas de informações entre os movimentos (havia uma comissão chamada UNO - União Nacional das Ocupações - que fazia o diálogo entre ocupações do país).

Logo nas primeiras assembleias, houve a criação de comissões, sendo elas descritas abaixo:

- Enfermaria: responsável por cuidados emergenciais com integrantes que apresentassem algum tipo de enfermidade;

- Segurança: responsável pelo cadastramento de alunos na ocupação e pela fiscalização para que apenas pessoas cadastradas transitassem pela área;

- Combate a opressões: prezava pela não existência de preconceitos como machismo, racismo e LGBTFobia. Percebe-se a necessidade dessa comissão pela fala abaixo:

Ali a gente tá num espaço que é pra realmente não ter opressão. [...] Por exemplo, já aconteceram situações de acabar que sempre eram as mesmas pessoas que tavam na limpeza. Eram sempre as minas, e tipo, negras que tavam limpando, e, ou uma galera assim, alguns meninos gays (E1).

- Alimentação: preparava a alimentação dos ocupantes que, por estarem no desempenho de suas funções, não podiam sair da ocupação para realizar as refeições no restaurante universitário. Para isso, recebiam doações em dinheiro ou em mantimentos dos apoiadores do movimento;

- Comunicação: era responsável pela comunicação oficial do movimento. Para isso, produziam conteúdos que seriam divulgados, principalmente na página do Facebook, já mencionada nesse artigo. Além disso, realizavam a comunicação com a mídia e organizavam o programa Minha Casa Minha Reitoria. Esse programa era transmitido ao vivo via streaming ${ }^{x}$ viabilizado pelas novas Tecnologias de Informação e Comunicação (TIC's) e objetivava informar sobre o trabalho 
realizado pelas comissões, discutir assuntos relacionados às pautas e responder às dúvidas das pessoas de fora;

- Finanças: cuidava da administração financeira do movimento, cujos recursos eram basicamente provenientes de doações;

- Articulação externa: atuava no estabelecimento de diálogos com a reitoria, sindicatos (como o dos professores) e com outras ocupações. Um de seus objetivos era apoiar ocupações em escolas secundaristas da cidade;

- Eventos e cultura: realizava eventos como palestras, oficinas, rodas de conversa e sarais para o público interno e externo à universidade;

- Cinema e audiovisual: produzia vídeos e animações sobre temas importantes no contexto do movimento e realizava sessões de cinema para a comunidade em geral;

- Articulação interna: Foi criada com o objetivo de realizar a integração entre as comissões, mas foi extinta no início da ocupação.

A adesão às comissões era voluntária e o ocupante poderia escolher aquela da qual desejava participar. Qualquer tipo de trabalho exercido era valorizado da mesma forma, não havendo funções mais ou menos importantes, assim como sugeriu Gutierrez (1988), ao entender que neste tipo de organização, não se justifica a divisão entre o trabalho manual e o intelectual, dada a concepção de homem adotada.

A respeito da organização interna, o entrevistado 2 comentou: "Muito tempo, a gente perdia muito tempo nas assembleias, falando de organização interna. De problema que acontecia, de problema de questão de segurança, problema em questão de limpeza, problema em questão de cozinha e assédio, essas coisas". Percebe-se por esta fala a complexidade de gerir coletivamente a organização.

As decisões eram tomadas em assembleia, por meio de votação, com exceção de questões mais simples que eram decididas no âmbito das comissões. A assembleia era o órgão deliberativo máximo do movimento, típico de estruturas organizativas autogestionárias (MISOCZKY; SILVA; FLORES, 2008). As assembleias aconteciam de segunda a sexta, às $22 \mathrm{~h}$ e duravam de 2 a 3 horas, em média, havendo dias em que ocorreram 3 assembleias:

Tudo era decidido por votação, desde a decisão, no final, da gente parar de comer, carne porque a gente não tinha dinheiro pra comprar carne e todo mundo vira vegetariano, porque foi um momento bem complicado da ocupação. Como a gente ia fazer o ato, se a gente ia apoiar ou se não ia, se a gente ia pra zona norte, se a gente ia pra o Duque de Caxias, para o João XXIII ${ }^{\mathrm{xi}}$ como a gente ia fazer, vai tirar uma nota sim, se vai tirar, se vai soltar a nota, vai conversar com a Reitoria, vai fazer isso[...] então tudo era decidido 
em assembleia. (E4)

O OcupaUF foi um espaço de discussões e diálogos entre os membros. Todos os participantes concordaram que a tomada de decisão foi realizada coletivamente, caracterizando uma forma de autogestão (SERVA, 1993; MISOCZKY, 2010).

$\mathrm{Na}$ assembleia, a mesa era composta por três membros: o responsável por fazer as inscrições de quem queria falar, o responsável por controlar o tempo de fala e o responsável por fazer a relatoria. Essa mesa era incumbida de mediar as discussões e manter a organização da assembleia: "Todos os dias essa mesa era rotativa e havia uma preocupação, assim, de não ficar repetindo as pessoas, isso correu bem" (E3). Pessoas da mesma comissão, ou do mesmo partido, não poderiam ocupar mais de uma cadeira conforme colocado pelo entrevistado 5 . Os participantes desta pesquisa declararam que todos poderiam participar de forma igualitária, denotando uma situação de solidariedade, democracia e equidade. Esses aspectos reforçam a presença da autogestão no movimento (MISOCZKY; SILVA; FLORES, 2008; PINHEIRO; PAULA, 2016).

Foi possível perceber ainda que as estruturas não eram rígidas, havendo reestruturação das comissões e migrações entre os membros das comissões. A fluidez das comissões e funções dos membros caracteriza o caráter temporário típico de práticas horizontalizadas, características de organizações autogestionárias (MISOCZKY; SILVA; FLORES, 2008). Segundo o entrevistado 4, "a ocupação era um ser vivo que ia crescendo e se modificando a cada dia, a cada manhã".

De acordo com os entrevistados, não existiam lideranças formais na ocupação. Entretanto alguns ocupantes citaram que havia alunos que se destacavam em momentos de tensão: "Então, quando rolava esses momentos de caos sempre tinha uma pessoa ali mais iluminada que tentava articular essas emoções pra galera acalmar e falar que não é assim que tentar dar uma voz a razão" (E7).

Na observação realizada no local, verificou-se que os estudantes estavam acampados em um saguão, localizado no prédio da reitoria. As salas utilizadas para os gabinetes da reitoria e pró-reitorias passaram a ser a sede das comissões. As assembleias eram realizadas no anfiteatro desse mesmo prédio. Os alunos responsáveis pela segurança vigiavam a entrada do local e, para que o pesquisador pudesse realizar a observação, foi necessário o acompanhamento de um dos ocupantes. 
Uma estudante mencionou ações realizadas no sentido da conscientização política da população: houve visitas em escolas, panfletagem nas ruas, conversas com os trabalhadores que estavam indo pro trabalho e foram realizados dois atos no centro da cidade. Além disso, os ocupantes tentaram sensibilizar os colegas de sala; os CAs e DAs levaram discussões para os Institutos e faculdades, foram convidados professores e outros profissionais que pudessem ensinar sobre temas relacionados. Houve também a produção do programa "Minha Casa, Minha Reitoria", criado na ocupação anterior e que foi retomado nessa ocupação. Essas ações tinham o objetivo de uma conscientização política não apenas dos membros do grupo OcupaUF, mas da sociedade em geral, característica essa que corrobora com o nível "mobilizações na esfera pública" proposto por Scherer-Warren (2006).

Os estudantes da ocupação participaram de manifestações nacionais realizadas em Belo Horizonte e em Brasília. Na ocasião dessas manifestações, a ocupação organizou um treinamento com presença obrigatória (para os que iriam participar dos atos) em que foram ensinadas medidas de segurança devido a repressão policial que possivelmente eles iriam sofrer. $\mathrm{O}$ entrevistado 8 comenta sobre um dos temas tratados no treinamento: "ensinaram a gente a diferenciar qual bomba era de lacrimogêneo ou de estilhaço. Porque se for a de estilhaço é para você correr porque aquilo te corta inteiro, se você não tiver de calça jeans é pior ainda. Ensinar a como agir, sabe?". Esse mesmo entrevistado discorreu sobre esses atos, nos quais ocorreram confrontos com a Guarda Nacional e Polícia Militar, respectivamente:

Quando a gente chegou no Senado, aconteceu alguma coisa longe de mim que a polícia começou a tacar muita bomba [...] estavam jogando bombas por helicóptero, e a gente não sabia o que fazia e nisso já tinha uma galera apanhando muito lá na frente, uma galera virando carro e polícia indo atrás, estava um caos total e a gente não sabia mais o que fazer e foi muito curto o ato porque não teve um ato pacífico e a polícia começou a repreender a gente, foi 15 minutos de ato e a polícia já começou a descer na gente. [...] O ato de $\mathrm{BH}$ foi ainda pior de repressão, porque a gente chegou lá e tava um ato super pacífico, a gente andou, gritou, correu [...] e aí a polícia começou a jogar bomba na gente. Em Brasília eles ficavam parados jogando bomba e a gente corria, em $\mathrm{BH}$ eles saíram correndo atrás da gente por quarteirões e nesse momento virou um caos [...] eu nunca corri tanto na minha vida, naquele dia eu fiquei realmente com medo (E8).

O fim do movimento, após 47 dias de ocupação, foi decidido em assembleia e divulgado em nota na página do movimento no Facebook. Os entrevistados relataram que as motivações para a desocupação passavam pelo esvaziamento contínuo, o cansaço e o stress gerados por viver em um ambiente improvisado, sem condições adequadas de descanso e 
alimentação, a greve dos professores que fez com que muitos alunos de fora da cidade tivessem que retornar para suas cidades, o fechamento do restaurante universitário devido à greve dos técnicos e a falta de dinheiro para a compra de alimentação. Além disso, percebeuse que a mobilização não estava sendo capaz de barrar a aprovação da PEC 241. Segundo o entrevistado 4, a ocupação era uma tática que gerou burburinho, informação e conscientização das pessoas, mas quando cumpriu essa função, não tinha mais motivos para continuar existindo.

Organizações autogestionárias buscam resultados não apenas econômicos, mas também sociais, políticos culturais e formativos. Isso pôde ser percebido ao analisar os ganhos do movimento OcupaUF. A maior parte dos estudantes avaliou que o movimento teve um saldo positivo, e para justificar, citaram as seguintes conquistas: aglutinou pessoas novas, mobilizou os DAs, foram realizados trabalhos de conscientização entre os estudantes, houve greve estudantil em alguns cursos, fizeram atos, dialogaram com as pessoas, trouxeram calouros que não conheciam o movimento estudantil e que entenderam a sua importância, conscientizaram pessoas de fora das universidade, produziram o canal Minha Casa, Minha Reitoria.

Sobre o fortalecimento do movimento estudantil, um entrevistado relatou:

A gente fez bastante grupo de estudo dentro da ocupação, a gente conseguiu fazer um movimento estudantil, a gente conseguiu descobrir coisas da Universidade [...] as pessoas são muito alheias ao que acontece lá dentro, ao que pode e ao que não pode, ao que a gente tem direito e não tem porque a Universidade não está preocupada em trazer isso pros alunos. Então foi muito produtivo nesse âmbito e quem participou do movimento conseguiu ter essa força e esse gás pra saber que é possível mudar algumas coisas [...] eu acho que o movimento estudantil agora tem grande chance de conseguir se articular nos próximos semestres, não enquanto movimento de ocupação mas enquanto movimento estudantil da Universidade mesmo para poder tá conseguindo nossas pautas, porque a gente não desistiu delas (E2).

Os entrevistados comentaram sobre a consciência da dificuldade de impedir que a PEC 241 fosse aprovada, mas apontaram a importância da mobilização da sociedade, conforme a fala da entrevistada 2, "A gente sabia sim, a gente não era muito iludido que a gente ia conseguir barrar a PEC, mas a gente acreditava na diferença que tinha de deixar a PEC passar sem resistência e com resistência" (E2). Os que não avaliaram positivamente o movimento citaram a falta de apoio dos estudantes e institutos e a falta de atingimento de objetivos concretos. 


\section{CONSIDERAÇÕES FINAIS}

O movimento estudantil, nos últimos anos, tem se demonstrado pulverizado, ao contrário do que era percebido nas manifestações ocorridas durante o século XX. Entretanto, as ações de ocupação de espaços relativos a escolas e universidades, promovidas pelos estudantes no ano de 2016 apontam para uma retomada da unificação desse movimento.

Diversamente da manifestação ocorrida em 2015 na instituição, quando estudantes também ocuparam a reitoria pleiteando questões internas, no caso estudado dessa pesquisa, houve uma articulação com o movimento nacional que se revelava. Nesse sentindo, é possível caracterizar esse movimento social como o terceiro nível proposto por Scherer-Warren (2006), "mobilizações de esfera pública". Nesse contexto, conforme observado pelas falas dos entrevistados, o objetivo foi ganhar notoriedade e abrangência na luta por questões que envolviam toda a população brasileira.

A respeito da estrutura organizativa do OcupaUF, foi possível perceber características da autogestão, como a assembleia enquanto órgão deliberativo máximo, igualdade de participação, já que qualquer integrante da ocupação tinha direito a voz e voto nas assembleias, tomada de decisão coletiva e nas práticas organizacionais horizontais (MISOCZKY; SILVA; FLORES; 2008).

Apesar de alguns estudantes apontarem certa falta de competência para articulação na busca pelo alcance das pautas, principalmente as internas, o movimento foi visto como positivo para a maioria dos entrevistados. Um dos pontos mais relevantes, citado como um legado da ocupação foi o fortalecimento do movimento estudantil, como forma organizacional de luta e de resistência, independentemente dos resultados específicos alcançados.

Como se pode perceber, a adoção de teorias tradicionais em Administração, baseadas em modelos organizacionais tipo burocráticos não se mostram adequadas à compreensão de movimentos sociais como o aqui estudado. Assim, ao dar voz aos participantes, foi possível perceber como se constituiu a gestão dessa organização que apresentou características próprias e adequadas à sua realidade e às suas finalidades. 


\section{REFERÊNCIAS}

BARS, R.; TADA, C. "Ocupa Brasília” reafirma resistência contra PEC 55 e desmandos de Temer. Disponível em: < http://www.une.org.br/noticias/ocupa-brasilia-reafirma-resistenciacontra-pec-55-e-desmandos-de-temer/>. Acesso em: 23 jan. 2017.

BARROS, A. N. Movimento Estudantil como organização social detentora de projetos políticos. 2009. 128p. Dissertação (Mestrado em Administração)-Programa de Pós Graduação e Pesquisas em Administração da Universidade Federal de Minas Gerais, Belo Horizonte.

BARROS, A. N.; PAULA, A. P. P. Organização social como manifestação de projetos políticos: Revendo o estatuto dos Movimentos Sociais nos Estudos Organizacionais. In: Encontro da ANPAD, 32, 2008. Rio de Janeiro. Anais... Rio de Janeiro: ANPAD, 2008. Disponível em: < http://www.anpad.org.br/admin/pdf/EOR-C1600.pdf> . Acesso em: 01 abr. 2017.

BARROS, J. D.A. Os Falanstérios e a crítica da sociedade industrial: revisitando Charles Fourier. Mediações-Revista de Ciências Sociais, v. 16, n. 1, p. 239-255, 2011.

BRASIL. Lei $n^{0}$ 7398. Dispõe sobre a organização de entidades representativas dos estudantes de $1^{\circ}$ e $2^{\circ}$ graus e dá outras providências. Disponível em:

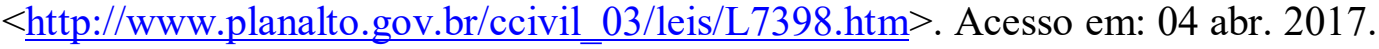

COSTA, C.S.B. Movimento Estudantil Contemporâneo: uma análise compreensiva das suas formas de atuação. 2004. 270 p. Tese (Doutorado em Sociologia) - Departamento de Ciências Sociais, Universidade Federa de Pernambuco, Recife.

COSTA, P. A. Experiências contra hegemônicas de organização do trabalho como práticas de resistência política. In: Congresso Brasileiro de Estudo Organizacionais, 3., 2015. Vitória.

Anais... Disponível em

$<$ https://drive.google.com/drive/folders/0B617ghJ2bLE2VDk4M3hjMUZVMUU> Acesso em: 15 Nov. 2016

FREIRE, S. M.. Movimento estudantil no Brasil: lutas passadas, desafios presentes. Revista Historia de la Educación Latinoamericana, v. 11, p. 131-146, 2008.

GIL, A.C. Como elaborar projetos de pesquisa. 4 ed. São Paulo: Atlas, 2002.

GUTIERREZ, G. Autogestão de empresas: considerações a respeito de um modelo possível. Revista de Administração de Empresas, v. 28, n. 2, p. 56-75, abr./jun. 1988.

MARTINS, F.S; RUIZ; M.J.F. O movimento estudantil e a democratização da educação. In: XVI Semana da Educação VI e Simpósio de Pesquisa e Pós-graduação em Educação. 2015. Londrina. Anais... Londrina: UEL, 2015. Disponível em: < http://www.uel.br/eventos/semanaeducacao/pages/arquivos/ANAIS/ARTIGO/PERSPECTIV AS\%20FILOSOFICAS/O\%20MOVIMENTO $\% 20$ ESTUDANTIL $\% 20 \mathrm{E} \% 20 \mathrm{~A} \% 20 \mathrm{DEMOCR}$ ATIZACAO\%20DA\%20EDUCACAO.pdf>. Acesso em: 24 abr. 2017. 
MESQUITA, M.R. Movimento estudantil brasileiro: Práticas militantes na ótica dos Novos Movimentos Sociais. Revista Crítica de Ciências Sociais, n.66, p.117-149. 2003. Disponível em: < https://rccs.revues.org/1151\#quotation> . Acesso em: 03 abr. 2017.

MISOCZKY, M.C. Das práticas não-gerenciais de organizar à organização para a práxis da libertação. In: MISOCZKY, M.C; FLORES, R.K; MORAES, J. (orgs). Organização e práxis libertadora. Porto Alegre: Dacasa Editora, 2010.

MISOCZKY, M. C.; FLORES, R. K.; SILVA, S. M. G. Estudos organizacionais e movimentos sociais: o que sabemos? Para onde vamos?. Cadernos EBAPE.BR, Rio de Janeiro, v. 6, n. 3, p. 1 a 14, set. 2008.

MISOCZKY, M. C.; SILVA, J. M.; FLORES, R. K. Autogestão e Práticas Organizacionais Horizontalizadas: Amplificando Sinais. In: V Encontro de Estudos Organizacionais da ANPAD. 5, 2008. Belo Horizonte. Anais... Belo Horizonte: ANPAD, 2008. Disponível em: $<$ http://www.anpad.org.br/diversos/trabalhos/EnEO/eneo_2008/2008_ENEO380.pdf >. Acesso em: 18 jan. 2017.

MOTTA, F. P. Burocracia e Autogestão: a proposta de Proudhon. São Paulo: Editora Brasiliense, 1981.

PINHEIRO, D. C.; PAULA, A. P. P. Auto Gestão e Práticas Organizacionais Transformadoras: Contribuições a partir de um caso empírico. Desenvolvimento em questão. Ed Unijuí. Ano 14, n. 33, p. 233-266, jan-mar, 2016.

SCHERER-WARREN, I. Das mobilizações às redes de movimentos sociais. Soc. estado, Brasília, v.21, n.1, pp.109-130, 2006.

SCHERER-WARREN, I. Manifestações de rua no Brasil 2013: encontros e desencontros na política. Cad. CRH. Salvador, v.27, n.71, pp.417-429, maio/ago. 2014.

SERVA, M. O fenômeno das organizações substantivas. Revista de Administração de empresas, São Paulo, v.33, n.2, p.36-43, mar-abr, 1993.

SILVA, T. V. Organizações Alternativas: Uma análise das práticas organizacionais de uma cooperativa de mídia social. In: Congresso Brasileiro de Estudo Organizacionais, 4, 2016. Porto Alegre. Anais... Disponível em <

https://anaiscbeo.emnuvens.com.br/cbeo/article/download/259/251> Acesso em: 30 Jan. 2016

TADA, C. Caravana de ocupações e movimento educacional vai parar Brasília dia 29/11. Disponível em: $<$ http://www.une.org.br/noticias/caravana-de-ocupacoes-e-movimentoeducacional-vai-parar-brasilia-dia-2911/>. Acesso em: 23 jan. 2017.

TOLEDO, D. A. C. Pensando categorias de análise para o exercício da prática da Autogestão. In: Encontro da ANPAD, 32, 2008. Rio de Janeiro. Anais... Disponível em: < http://www.anpad.org.br/admin/pdf/APS-C2496.pdf> Acesso em: 30 jan. 2017. 
UNE. Memória. Disponível em: < http://www.une.org.br/memoria/historia/> . Acesso em 03 mar. 2017.

UNIFESP. História cronológica do Movimento Estudantil. Disponível em: < http://dce.unifesp.br/historiame>. Acesso em 24 abr. 2017.

UNICAP. Saiba a história do movimento estudantil. Disponível em: $<$ http://www.unicap.br/webjornalismo/metanoia/?p=74> $>$. Acesso em: 30 mar. 2017.

VERGARA, S.C. Métodos de pesquisa em administração. 5 ed. São Paulo: Atlas, 2012.

\footnotetext{
${ }^{\mathrm{i}}$ Barros (2009) ressalta que o termo organizações produtivas não engloba experiências referentes à economia solidária.

${ }^{\text {ii }}$ Unidades sociais compostas por um edifício onde cerca de 1500 pessoas viveriam em regime de cooperativa, conforme proposta de Charles Fourier (BARROS,2011)
}

iii Proposta de Emenda a Constituição 55: Altera o Ato das Disposições Constitucionais Transitórias, para instituir o Novo Regime Fiscal, e dá outras providências. Para mais informações: https://www25.senado.leg.br/web/atividade/materias/-/materia/127337

iv Proposta de Emenda a Constituição 241: Altera o Ato das Disposições Constitucionais Transitórias, para instituir $\quad 0$ Novo Regime Para mais informações: http://www.camara.gov.br/proposicoesWeb/fichadetramitacao?idProposicao=2088351

${ }^{v}$ Medida Provisória 746: Institui a Política de Fomento à Implementação de Escolas de Ensino Médio em Tempo Integral, altera a Lei $\mathrm{n}^{\circ}$ 9.394, de 20 de dezembro de 1996, que estabelece as diretrizes e bases da educação nacional, e a Lei $\mathrm{n}^{\circ} 11.494$ de 20 de junho 2007, que regulamenta o Fundo de Manutenção e Desenvolvimento da Educação Básica e de Valorização dos Profissionais da Educação, e dá outras providências. Para mais informações: https://www25.senado.leg.br/web/atividade/materias/-/materia/126992

${ }^{v i}$ Proposta de Emenda a Constituição 53: Altera os arts. $9^{\circ}$ e 37 da Constituição Federal para estabelecer a educação como serviço essencial. Para mais informações: https://www12.senado.leg.br/ecidadania/visualizacaomateria?id=127317

${ }^{\text {vii }}$ Medida provisória 735: Altera as Leis $\mathrm{n}^{\circ} 5.655$, de 20 de maio de 1971, $\mathrm{n}^{\mathrm{o}} 10.438$, de 26 de abril de 2002, $\mathrm{n}^{\mathrm{o}}$ 12.783, de 11 de janeiro de 2013, no 9.074, de 7 de julho de 1995, e $\mathrm{n}^{\circ}$ 9.491, de 9 de setembro de 1997, e dá outras providências. Para mais informações: https:/www25.senado.leg.br/web/atividade/materias//materia/126236

viii Conselho Superior. O Conselho Superior é o órgão máximo de deliberação interna da Instituição estudada, com definição estatutária, possuindo função normativa, deliberativa e de planejamento.

${ }^{\text {ix }}$ Regimento Acadêmico da graduação

${ }^{x}$ Forma de transmissão de som e imagem (áudio e vídeo) que não necessita de efetuar downloads

${ }^{x i}$ Escolas de nível médio da cidade onde ocorreu o OcupaUF. 